\title{
Fatigue failure load of two resin-bonded zirconia-reinforced lithium silicate glass-ceramics: Effect of ceramic thickness
}

\author{
Jaiane Bandoli Monteiro ${ }^{a}$, Hilton Riquieri ${ }^{a}$, Catina Prochnow ${ }^{b}$, \\ Luís Felipe Guilardi ${ }^{b}$, Gabriel Kalil Rocha Pereira ${ }^{b, c}$, \\ Alexandre Luiz Souto Borges ${ }^{d}$, Renata Marques de Melo ${ }^{d}$, \\ Luiz Felipe Valandro ${ }^{b, *}$
}

a São Paulo State University (UNESP), Science and Technology Institute, São José dos Campos, São Paulo, Brazil

${ }^{\mathrm{b}}$ Faculty of Odontology, Federal University of Santa Maria, Santa Maria, Rio Grande do Sul, Brazil

c School of Dentistry, Meridional Faculty — IMED, Passo Fundo, Rio Grande do Sul, Brazil

d Department of Dental Materials and Prosthodontics, São Paulo State University (UNESP), Institute of Science and Technology, São José dos Campos, São Paulo, Brazil

\section{A R T I C L E I N F O}

Article history:

Received 18 December 2017

Received in revised form

8 March 2018

Accepted 12 March 2018

Keywords:

Dental ceramics

Fatigue

Finite element analysis

Glass ceramics

Mechanical behavior

Monolithic full-contour restorations

Staircase method

\begin{abstract}
A B S T R A C T
Objectives. To evaluate the effect of ceramic thickness on the fatigue failure load of two zirconia-reinforced lithium silicate (ZLS) glass-ceramics, adhesively cemented to a dentin analogue material.

Methods. Disc-shaped specimens were allocated into 8 groups $(n=25)$ considering two study factors: ZLS ceramic type (Vita Suprinity - VS; and Celtra Duo - CD), and ceramic thickness $(1.0 ; 1.5 ; 2.0$; and $2.5 \mathrm{~mm})$. A trilayer assembly $(\phi=10 \mathrm{~mm}$; thickness $=3.5 \mathrm{~mm})$ was designed to mimic a bonded monolithic restoration. The ceramic discs were etched, silanized and luted (Variolink N) into a dentin analogue material. Fatigue failure load was determined using the Staircase method $(100,000$ cycles at $20 \mathrm{~Hz}$; initial fatigue load $\sim 60 \%$ of the mean monotonic load-to-failure; step size $\sim 5 \%$ of the initial fatigue load). A stainless-steel piston $(\phi=40 \mathrm{~mm})$ applied the load into the center of the specimens submerged in water. Fractographic analysis and Finite Element Analysis (FEA) were also performed.

Results. The ceramic thickness influenced the fatigue failure load for both ZLS materials: Suprinity ( $716 \mathrm{~N}$ up to $1119 \mathrm{~N}$ ); Celtra ( $404 \mathrm{~N}$ up to $1126 \mathrm{~N}$ ). FEA showed that decreasing ceramic thickness led to higher stress concentration on the cementing interface.

Significance. Different ZLS glass-ceramic thicknesses influenced the fatigue failure load of the bonded system (i.e. the thicker the glass ceramic is, the higher the fatigue failure load will be). Different microstructures of the ZLS glass-ceramics might affect the fatigue behavior.
\end{abstract}

\footnotetext{
* Corresponding author at: Federal University of Santa Maria, Faculty of Odontology, Prosthodontics Unit, Floriano Peixoto, 1184, 97015 -372 Santa Maria, Brazil.

E-mail addresses: jaiane.monteiro@ict.unesp.br (J.B. Monteiro), hilton.riquieri@terra.com.br (H. Riquieri), catinaprochnow@hotmail.com (C. Prochnow), luisfguilardi@hotmail.com (L.F. Guilardi), gabrielkrpereira@hotmail.com (G.K.R. Pereira), aleborges@ict.unesp.br (A.L.S. Borges), marquesdemelo@gmail.com (R.M. de Melo), lfvalandro@hotmail.com (L.F. Valandro). https://doi.org/10.1016/j.dental.2018.03.004

0109-5641/@ 2018 The Academy of Dental Materials. Published by Elsevier Ltd. All rights reserved.
} 
FEA showed that the thicker the glass ceramic is, the lower the stress concentration at the tensile surface will be.

( 2018 The Academy of Dental Materials. Published by Elsevier Ltd. All rights reserved.

\section{Introduction}

Nowadays, the concept of monolithic full-contour restorations using Computer Aided Design/Computer Aided Manufacturing (CAD/CAM) technology has been considered as an alternative to the conventional restorative approaches for fixed dental prostheses (FDPs) [1]. This restorative alternative allows a substantial reduction of the ceramic thickness in accordance with the concept of minimally invasive dentistry, which emphasizes the use of high-resistance materials in association with adhesive luting techniques to restore teeth [2]. Thus, care must be taken in the minimum ceramic thickness required to ensure adequate mechanical performance, and for which information is not available in the literature.

Zirconia-reinforced lithium silicate (ZLS) glass-ceramics have been introduced into the dental market [1]. They consist of a new generation of ceramics, which allegedly combine glass-ceramic aesthetic performance and improved mechanical properties due to the presence of metasilicate and zirconia crystals into the glass matrix $[3,4]$.

Currently, there are two different ZLS ceramic materials available for application in Restorative Dentistry, being both of them essentially composed by two crystal phases embedded into a glassy matrix. One of the crystalline phases consists of submicrometric lithium metasilicate $\left(\mathrm{Li}_{2} \mathrm{SO}_{3}\right)$ crystallites in a round and slightly elongated shape, while the other is a lithium orthophosphate $\left(\mathrm{Li}_{3} \mathrm{PO}_{4}\right)$ in a round shape with nanometric size [1]. According to Belli et al. [1], one of the major differences between the two materials is the size of lithium metasilicate crystals ( $\mathrm{Li}_{2} \mathrm{SO}_{3}$ phase), which appears to have a bigger size in Celtra Duo (up to $\sim 1 \mu \mathrm{m}$ in length) than in Suprinity $(\sim 0.5 \mu \mathrm{m})$. Hence, theoretically it could be expected that different microstructures could affect the crack propagation and the fatigue behavior of the materials, as existing literature $[5,6]$ stated that bigger grain sizes would lead to decreased mechanical performance in comparison to a material with same composition and smaller grain size.

When compared to the conventional lithium disilicate ceramic (without zirconia reinforcement), ZLS glass-ceramics present a lower percentage of crystal phase content (40-50\% in comparison to $70 \%$ of a conventional lithium disilicate glassceramic) [4,7]. However, crystals within ZLS materials are smaller and the glassy matrix is reinforced due to highly dispersed zirconium dioxide ( $10 \%$ in weight), which is assumed to enhance the strength of the glassy phase $[1,4,8]$.

It is important to highlight that the presence of the glassy matrix in their structures enables this class of ceramics (ZLS) to be etched by hydrofluoric acid even with the presence of zirconium dioxide crystals. This allows the creation of micro-mechanical retentions on the cementing surface and resin bond improvement [9], different from the characteristics observed on the zirconia polycrystals based materials (nonetchable).

The occlusal thickness of ceramic restorations may affect the fracture resistance, since the strength of ceramic is inversely related to the square of ceramic thickness [10]. Chen et al. [11] have showed a linear relation between the ceramic thickness and the fracture resistance for a lithium disilicatebased glass ceramic, however they stated that between 0.5 and $1.5 \mathrm{~mm}$ thick the fracture resistance did not change much. Also, it is well known that better bonding can lead to higher fracture resistance, as reported by a previous study in which higher fracture resistance was found to ceramic crowns luted with resin cements compared to other luting agents [12]. In this sense, especially for thinner ceramic restorations, the adhesive protocol adopted might play a crucial role in the final strength of the assembly; aspects that currently have not been corroborated for ZLS ceramics yet.

Importantly, glass-ceramic materials might fail when subjected to dynamic and intermittent loading stresses owing to their brittle behavior [13]. Fatigue failure is considered as a fracture of the material due to progressive brittle cracking under repeated cyclic stresses at intensities below the material's normal strength [14]. Many in vitro studies have been developed involving the application of cyclic loads under moist environments to partly reproduce the clinical condition, as an attempt to infer the survival probability of ceramic restorations under different conditions [15-19]. In addition, Kelly et al. [20] developed an in vitro test assembly that better simulates the failure mechanism and stress state observed in clinically retrieved failed prostheses (e.g. radial cracks starting from the cementation surface - tensile side) [21].

Until now, data are scarce about the fatigue behavior of the existing ZLS glass-ceramics, specially concerning the effect of different thicknesses on the fatigue load-bearing ability of these materials. Therefore, this study aimed to evaluate and compare the influence of ceramic thickness on the fatigue failure load of two ZLS glass-ceramics adhesively cemented to a dentin analogue material. The tested hypotheses were that (1) the increase in ceramic thickness would increase the fatigue failure load of ZLS glass-ceramics; (2) the two ZLS glassceramics with different microstructures will present similar fatigue failure loads for similar restoration thicknesses.

\section{Materials and methods}

Information regarding the commercial name, manufacturers, composition, batch number and respective expiration date from all materials used in this study are described in Table 1. 
Table 1 - Materials used in this study with their respectively manufacturers, composition, batch numbers, and validity.

\begin{tabular}{|c|c|c|c|c|}
\hline Material & Manufacturer & Composition & Batch No. & Validity \\
\hline Vita Suprinity ${ }^{\mathrm{a}}$ & $\begin{array}{l}\text { Vita Zahnfabrik H. Rauter GmbH \& Co., } \\
\text { Bad Säckingen, Germany }\end{array}$ & $\begin{array}{l}\text { Zirconia reinforced lithium silicate } \\
\text { glass-ceramic }\left(\mathrm{SiO}_{2}, \mathrm{Li}_{2} \mathrm{O}, \mathrm{K}_{2} \mathrm{O}, \mathrm{P}_{2} \mathrm{O}_{5}, \mathrm{Al}_{2} \mathrm{O}_{3} \text {, }\right. \\
\mathrm{ZrO}_{2}, \mathrm{CeO}_{2} \text {, pigments) }\end{array}$ & 49270 & Indeterminate \\
\hline Celtra Duo ${ }^{b}$ & $\begin{array}{l}\text { Degudent GmbH, Hanau, Wolfgang, } \\
\text { Germany }\end{array}$ & $\begin{array}{l}\text { Fully-sintered lithium silicate/phosphate } \\
\text { (LSP) glass-ceramic }\left(\mathrm{SiO}_{2}, \mathrm{P}_{2} \mathrm{O}_{5}, \mathrm{Al}_{2} \mathrm{O}_{3}, \mathrm{Li}_{2} \mathrm{O} \text {, }\right. \\
\mathrm{K}_{2} \mathrm{O}, \mathrm{ZrO}_{2}, \mathrm{CeO}_{2}, \mathrm{Na}_{2} \mathrm{O}, \mathrm{Tb}_{4} \mathrm{O}_{7}, \mathrm{~V}_{2} \mathrm{O}_{5}, \mathrm{Pr}_{6} \mathrm{O}_{11} \text {, } \\
\mathrm{Cr}, \mathrm{Cu}, \mathrm{Fe}, \mathrm{Mg}, \mathrm{Mn}, \mathrm{Si}, \mathrm{Zn}, \mathrm{Ti}, \mathrm{Zr}, \mathrm{Al}) \text {. }\end{array}$ & 18018171 & 05/2019 \\
\hline $5 \%$ Hydrofluoric acid & $\begin{array}{l}\text { Acid Gel 5\%, Maquira Ind. Dental Products } \\
\text { S.A., Maringá, Brazil }\end{array}$ & $\begin{array}{l}\text { Hydrofluoric acid } 5 \% \text {, thickening agent, red } \\
\text { dye and purified water. }\end{array}$ & 039816 & 07/2018 \\
\hline Monobond N & Ivoclar Vivadent, Schaan, Liechtenstein & $\begin{array}{l}\text { Alcohol solution of silane methacrylate, } \\
\text { phosphoric acid methacrylate and sulphide } \\
\text { methacrylate }\end{array}$ & U29879 & 07/2017 \\
\hline Excite F DSC & Ivoclar Vivadent, Schaan, Liechtenstein & $\begin{array}{l}\text { HEMA, dimethacrylate, phosphonic acid } \\
\text { acrylate, highly dispersed silicone dioxide, } \\
\text { initiators, stabilizers and potassium } \\
\text { fluoride in an alcohol solution, initiators }\end{array}$ & U52335 & $05 / 2018$ \\
\hline Variolink N Base & Ivoclar Vivadent, Schaan, Liechtenstein & Bis-GMA, urethane dimethacrylate, & V00666 & $04 / 2018$ \\
\hline Variolink N Catalyst & & $\begin{array}{l}\text { triethylene glycol dimethacrylate, barium } \\
\text { glass, ytterbium trifluoride, } \\
\text { Ba-Al-fluorosilicate glass, spheroid mixed } \\
\text { oxide, initiators, stabilizers and pigments }\end{array}$ & U48611 & $04 / 2018$ \\
\hline
\end{tabular}

a VITA SUPRINITY ${ }^{\circledR}$, Technical and scientific documentation (2014).

b CELTRA DUO ${ }^{\circledR}$, Celtra Block for Cerec and InLab (2014).

\section{Table 2 - Experimental design according to the final thickness of the assemblies.}

\begin{tabular}{llll} 
Material & Ceramic thickness $(\mathrm{mm})$ & Groups' codes & Dentin analogue thickness $(\mathrm{mm})$ \\
\hline Vita Suprinity & $1.0 \mathrm{~mm}$ & VS 1.0 & $2.5 \mathrm{~mm}$ \\
& $1.5 \mathrm{~mm}$ & VS 1.5 & $2.0 \mathrm{~mm}$ \\
& $2.0 \mathrm{~mm}$ & VS 2.0 & $1.5 \mathrm{~mm}$ \\
& $2.5 \mathrm{~mm}$ & VS 2.5 & $1.0 \mathrm{~mm}$ \\
Celtra Duo & $1.0 \mathrm{~mm}$ & CD 1.0 & $2.5 \mathrm{~mm}$ \\
& $1.5 \mathrm{~mm}$ & CD 1.5 & $2.0 \mathrm{~mm}$ \\
& $2.0 \mathrm{~mm}$ & CD 2.0 & $1.5 \mathrm{~mm}$ \\
& $2.5 \mathrm{~mm}$ & CD 2.5 & $1.0 \mathrm{~mm}$ \\
\hline
\end{tabular}

\subsection{Specimen preparation}

CAD-CAM pre-fabricated ceramic blocks of Vita Suprinity (VITA Zahnfabrik H. Rauter GmbH \& Co., Bad Säckingen, Germany) and Celtra Duo (Degudent GmbH, Hanau, Wolfgang, Germany) were shaped into cylinders $(\phi=10 \mathrm{~mm})$ using a polishing machine (Ecomet 250 Grinder Polisher, Buehler; Lake Bluff, Illinois, USA). The cylinders were cut with a diamond blade under water-cooling (Isomet 1000, Buehler), resulting in 200 discs ( $n=100$ for each ZLS ceramic) of different thicknesses $(n=25)$ (Table 2). The occlusal surfaces of the discs were polished with 600- and 1200-grit silicon carbide (SiC) papers (3M, Sumaré, Brazil). Afterwards, they were cleaned with isopropyl alcohol in an ultrasonic bath (5 min), and crystallized in a furnace according to the manufacturer's instructions (Initial chamber temperature $-400^{\circ} \mathrm{C}$; time at the initial temperature $-8 \mathrm{~min}$; temperature rate increase $55^{\circ} \mathrm{C} / \mathrm{min}$; crystallization temperature for Vita Suprinity of $840^{\circ} \mathrm{C}$ for $8 \mathrm{~min}$ and Celtra Duo of $830^{\circ} \mathrm{C}$ for $10 \mathrm{~min}$; ending temperature for Vita Suprinity of $680^{\circ} \mathrm{C}$ and for Celtra Duo of $700^{\circ} \mathrm{C}$ - using VACUMAT 6000 MP, VITA for Vita Suprinity and MULTIMAT, Dentsply Sirona for Celtra Duo).

The epoxy resin sheet $(150 \mathrm{~mm} \times 350 \mathrm{~mm}$ ) (Carbotec $\mathrm{GmbH}$ \& Co. KG, Königs Wusterhausen, Germany) had an established standardized thickness $(2.5 \mathrm{~mm})$. Thus, it was machined in a conventional lathe (Nardini, Americana, São Paulo, Brazil) to acquire the discs with each thickness used in this study (1.0, $1.5,2.0,2.5 \mathrm{~mm})$, resulting in 200 epoxy resin discs. They were also cleaned with isopropyl alcohol in an ultrasonic bath for $5 \mathrm{~min}$.

\subsection{Experimental design and cementation procedure}

Pairs of discs (ceramic and epoxy resin) were randomly assigned into four groups $(n=25)$ from each ZLS ceramic in accordance to the thickness factor (Table 2). The test assembly reproduced an occlusal restoration [11,22], which had a final diameter of $10 \mathrm{~mm}$ (average dimension of molars) [23] and a final thickness of $3.5 \mathrm{~mm}$ (ceramic thickness + epoxy resin thickness $=3.5 \mathrm{~mm}$ ), which was chosen as being equivalent to the average thickness from the roof of the pulp chamber to the occlusal surface [24].

The cementation surfaces of the ceramic and of the resin epoxy were etched with 5\% hydrofluoric acid (Acido Gel 5\%, Maquira Ind. Dental Products S.A., Maringá, Brazil) for 30 and $60 \mathrm{~s}$, respectively, followed by ultrasonic cleaning in distilled water ( $5 \mathrm{~min}$ ). After etching, a thin coat of silane (Monobond N, Ivoclar Vivadent, Schaan, Liechtenstein) was applied with a 
Table 3 - Mean monotonic load-to-failure, initial load for fatigue test ( $60 \%$ of monotonic mean load-to-failure), step size ( $5 \%$ of initial fatigue load). Fatigue failure load data: mean fatigue failure load $\left(\mathrm{L}_{\mathrm{f}}\right)$, standard deviation (SD), and $95 \%$ confidence interval (CI) according to Dixon and Mood [30].

\begin{tabular}{|c|c|c|c|c|c|}
\hline \multirow[t]{2}{*}{ Groups } & \multirow{2}{*}{$\begin{array}{l}\text { Mean monotonic } \\
\text { load-to-failure }(\mathrm{N})\end{array}$} & \multirow{2}{*}{$\begin{array}{l}\text { Initial load for } \\
\text { fatigue test }(\mathrm{N})\end{array}$} & \multirow[t]{2}{*}{ Step size $(\mathrm{N})$} & \multicolumn{2}{|c|}{ Fatigue failure load $(\mathrm{N})$} \\
\hline & & & & $\mathrm{L}_{\mathrm{f}} \pm \mathrm{SD}^{*}$ & $95 \% \mathrm{CI}$ \\
\hline VS 1.0 & 1240.3 & 730 & 36 & $716.5 \pm 95.5^{\mathrm{A}^{* *}}$ & $654.92-778.08$ \\
\hline VS 1.5 & 1529.9 & 900 & 45 & $907.5 \pm 34.5^{\mathrm{B}^{* *}}$ & $884.05-930.95$ \\
\hline VS 2.0 & 1865.5 & 1097 & 55 & $959.5 \pm 81.8^{\mathrm{BC}^{* *}}$ & $908.21-1010.79$ \\
\hline VS 2.5 & 1963.3 & 1155 & 58 & $1119.6 \pm 241.7^{C}$ & $974.29-1264.82$ \\
\hline CD 1.0 & 885.8 & 521 & 26 & $404.0 \pm 43.3^{\mathrm{a}^{* *}}$ & $375.47-432.57$ \\
\hline CD 1.5 & 1139.8 & 670 & 33.5 & $628.1 \pm 79.6^{\mathrm{b}^{* *}}$ & $576.83-679.42$ \\
\hline CD 2.0 & 1333.0 & 784 & 39 & $764.5 \pm 43.9^{c^{* *}}$ & $736.36-792.64$ \\
\hline CD 2.5 & 1995.6 & 1174 & 59 & $1126.8 \pm 80.2^{\mathrm{d}}$ & $1078.09-1175.51$ \\
\hline
\end{tabular}

microbrush to the pre-treated ceramic surfaces, and the material was allowed to react for $60 \mathrm{~s}$. The remaining excesses were dispersed with a gentle air-stream ( $5 \mathrm{~s}$ ). For the resin epoxy, a thin layer of adhesive material (Excite F DSC, Ivoclar Vivadent) was actively applied on the surfaces (10 s), followed by gentle air-drying to remove the excesses.

The cementation procedure was equal for all groups. The dual resin cement (Variolink N Base and Catalyst, Ivoclar Vivadent) was applied in the ratio of 1:1, and then mixed for $10 \mathrm{~s}$ according to the manufacturer's recommendation. A load of $7.5 \mathrm{~N}$ was applied on the occlusal surface of the assemblies, the cement excess was removed, and light-activation was performed for $10 \mathrm{~s}$ on each bond interface side $\left(0^{\circ}, 90^{\circ}, 180^{\circ}\right.$, and $270^{\circ}$ ) with a LED curing light (high intensity of $1000 \mathrm{~mW} / \mathrm{cm}^{2}$; wavelength ranging from 395 to $480 \mathrm{~nm}$ - Valo, Ultradent Products, South Jordan, Utah, USA). After removing the load, another light-activation was performed on the occlusal side (20 s).

The cemented assemblies were stored in a sealed vessel with distilled water at room temperature for 7 days until performing the fatigue tests.

\subsection{Fatigue failure load test - Staircase method}

Firstly, monotonic load-to-failure tests (EMIC DL 2000, Sao José dos Pinhais, Brazil) by applying an increasing compressive load $(1 \mathrm{~mm} / \mathrm{min})$ until the radial crack occurred were performed in five specimens per group to determine the initial fatigue load ( $\sim 60 \%$ of the mean monotonic load-to-failure) and the step size ( $\sim 5 \%$ of initial fatigue load) for each condition under the fatigue test (Table 3).

Then, twenty specimens $(n=20)$ of each condition were subjected to an cyclic fatigue test under water in an electrodynamic machine (Instron ElectroPuls E3000, Instron Corporation, Norwood, MA, United States). A stainless-steel sphere $(\phi=40 \mathrm{~mm})[20,22,25,26]$ was used to apply the load at the center of the specimen (i.e., center of the occlusal surface), which was positioned inside an attached cylindrical metal ring stabilized in a flat steel base. An adhesive tape $(110 \mu \mathrm{m})$ was fixed on the occlusal side of the specimens to improve contact with the sphere [27], and an additional thin sheet of a non-rigid material (cellophane, $2.5 \mu \mathrm{m}$ ) was placed between the piston and the specimen to better distribute the contact surface pressure according to previous studies using the same methodology $[22,28]$.

The fatigue failure load was determined using the staircase method (100,000 load pulses; $20 \mathrm{~Hz}$ ) described by Collins [29]. The load was applied with the amplitude ranging from a minimum of $10 \mathrm{~N}$ (to maintain the piston in an intimate contact with the specimen) to the maximum load attributed for each specimen in every step. The first specimen of each group was tested at an initial load close to the estimated fatigue failure load ( $60 \%$ of mean monotonic load-to-failure) until it either failed or runout (survival) at the predetermined cycles $\left(10^{5}\right.$ cycles). If the specimen failed, the load level was decreased by a preselected increment (step size $\sim 5 \%$ of the initial load for fatigue test), and the second specimen was tested at this lower load level. However, if the specimen survived, the load level was increased by the preselected increment (step size), and the following specimen was tested at this higher load level. This procedure was repeated until 20 samples per group were submitted to the fatigue failure load test.

After testing, the mean fatigue failure load $\left(\mathrm{L}_{\mathrm{f}}\right)$, standard deviation (SD) and 95\% confidence interval were calculated using the Dixon and Mood method [30], which involves maximum-likelihood estimation, assuming that data follows a normal distribution [29]. This methodology was previously well described in the literature [16,18,22,31].

\subsection{Fractographic analysis}

After fatigue tests, all the specimens were analyzed for contact damage and the determination of the crack direction. All the fractured specimens (radial cracks) were perpendicularly cut in two halves to the crack direction using a precision saw machine (Isomet 1000), and analyzed in a stereomicroscope (Discovery V20, Carl Zeiss, Gottingen, Germany) to determine the crack origin and its propagation. One representative specimen of each group was cleaned with isopropyl alcohol and dried in an oven (Olidef, Ribeirão Preto, São Paulo, Brazil) for further analysis in a Scanning Electron Microscope (SEM). Next, the specimens were placed on an aluminum platform 
Table 4 - Material properties used in the FEA models, and layer thicknesses attributed for each material.

\begin{tabular}{llllll} 
Structure/material & Suprinity & Celtra Duo & $\begin{array}{l}\text { Dentin analogue } \\
\text { material }\end{array}$ & Variolink N & $\begin{array}{l}\text { Stainless-steel sphere } \\
\text { - supporting ring }\end{array}$ \\
\hline Young's modulus (GPa) & $65.6^{\mathrm{a}}$ & $61.0^{\mathrm{b}}$ & $18.0^{\mathrm{c}}$ & $8.3^{\mathrm{d}}$ & $195.0^{\mathrm{c}}$ \\
Poisson ratio & $0.23^{\mathrm{a}}$ & 0.30 & $0.30^{\mathrm{c}}$ & $0.3^{\mathrm{d}}$ & $0.30^{\mathrm{c}}$ \\
Layer thickness & 1.0 & 1.0 & 2.5 & 0.1 & \\
$(\mathrm{~mm})$ & 1.5 & 1.5 & 2.0 & 0.1 & 0.1 \\
& 2.0 & 2.0 & 1.5 & 0.1 & \\
\hline
\end{tabular}

${ }^{a}$ Ref.[42].

b Ref. [43].

c Ref. [11]

d Ref. [44].
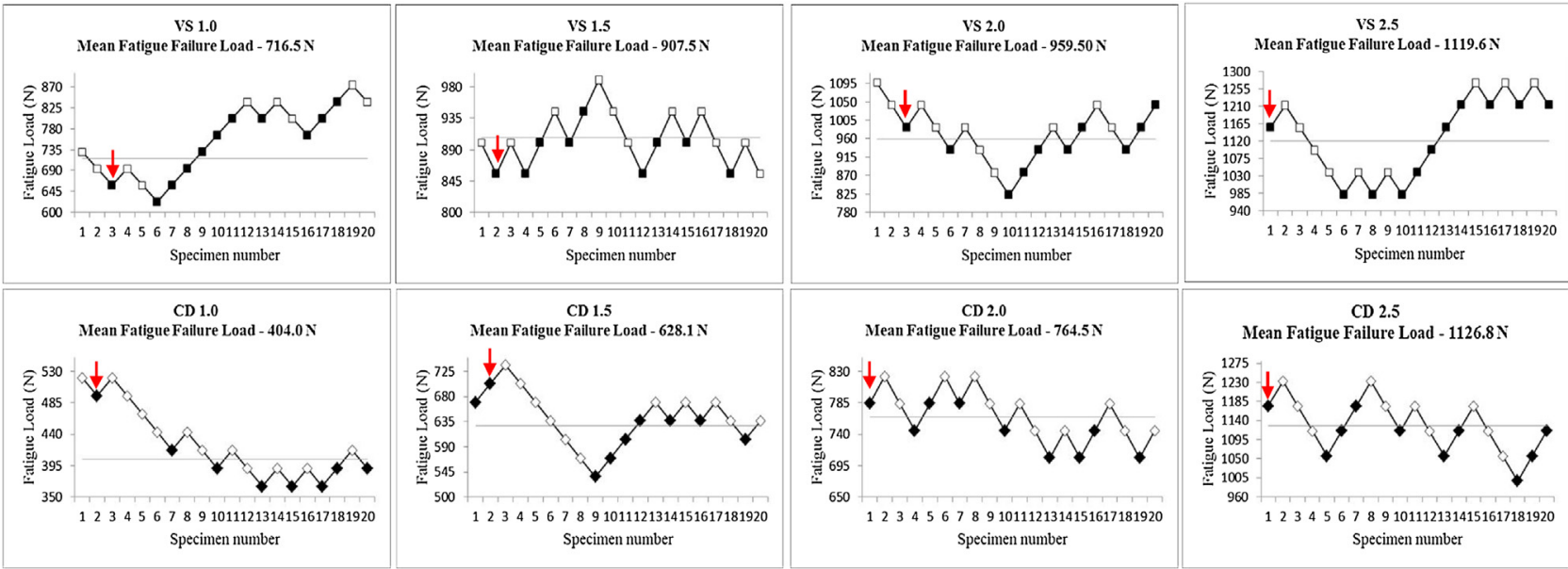

Fig. 1 - Staircase sensitivity test results during mechanical cycling $(100,000$ cycles at $20 \mathrm{~Hz})$ of ceramic discs adhesively cemented to dentin analogue material. First row: results for different thicknesses of Suprinity (VS); second row: different thicknesses of Celtra Duo (CD). Red arrows indicate the load level at which the up-and-down character started. (For interpretation of the references to colour in this figure legend, the reader is referred to the web version of this article.)

(stub) with a double-sided conductive carbon tape, metalized (Emitech SC7620, Quorum Technologies Ltd., Laughton, UK) with a thin layer of gold alloy and observed in SEM (Inspect S50, FEI, Brno, Czech Republic) at 500x, 1000×, and 2500× magnification.

\subsection{Finite Element Analysis - FEA}

A computer software (ANSYS 17.2, ANSYS Inc., Houston, TX, USA) was used to perform the tridimensional FEA. 3D geometries for all tested materials and thicknesses were modeled in CAD Rhinoceros (version 5.0 SR8 McNell, North America, Seattle, WA, USA) according to the experimental setup. The cement layer between the ceramic and the epoxy resin was established as $0.1 \mathrm{~mm}$ for all groups; the interface between connected layers was modeled assuming a perfect bonding between the substrates. A contact surface between sphere/specimen was modeled with a friction coefficient of 0.25 . Nonlinear analysis has become an increasingly powerful approach to predict stress and strain within structures in a realistic situation that cannot be solved by a linear static model [32].

The geometric models were meshed with quadratic tetrahedral elements (33,957 elements and 130,199 nodes). All materials were considered homogeneous, isotropic, and linear elastic. The properties (Young's modulus and Poisson's ratio) used in the FEA are presented in Table 4. The Poisson's ratio of Celtra Duo was assumed 0.30, and it means a linear behavior of the material. Maximum Principal Stress (MPS) was used as failure criteria since glass-ceramics are much stronger in compression than in tensile. The mean fatigue failure load of each group was used to calculate the stress distribution and MPS.

\section{Results}

\subsection{Fatigue failure load}

Parameters for the staircase test such as mean monotonic load-to-failure, initial load of the fatigue tests ( $60 \%$ of mean monotonic load-to-failure), step size ( $\sim 5 \%$ of initial fatigue load), and fatigue results are presented in Table 3 . The patterns of runouts (survivals) and failures for each group are shown in Fig. 1. In relation to the different thicknesses, both ZLS materials showed an increase in mean fatigue failure load with an increase in ceramic thickness (Table 3). Statistical differences could be detected between the different ZLS ceramic types (Table 3). 

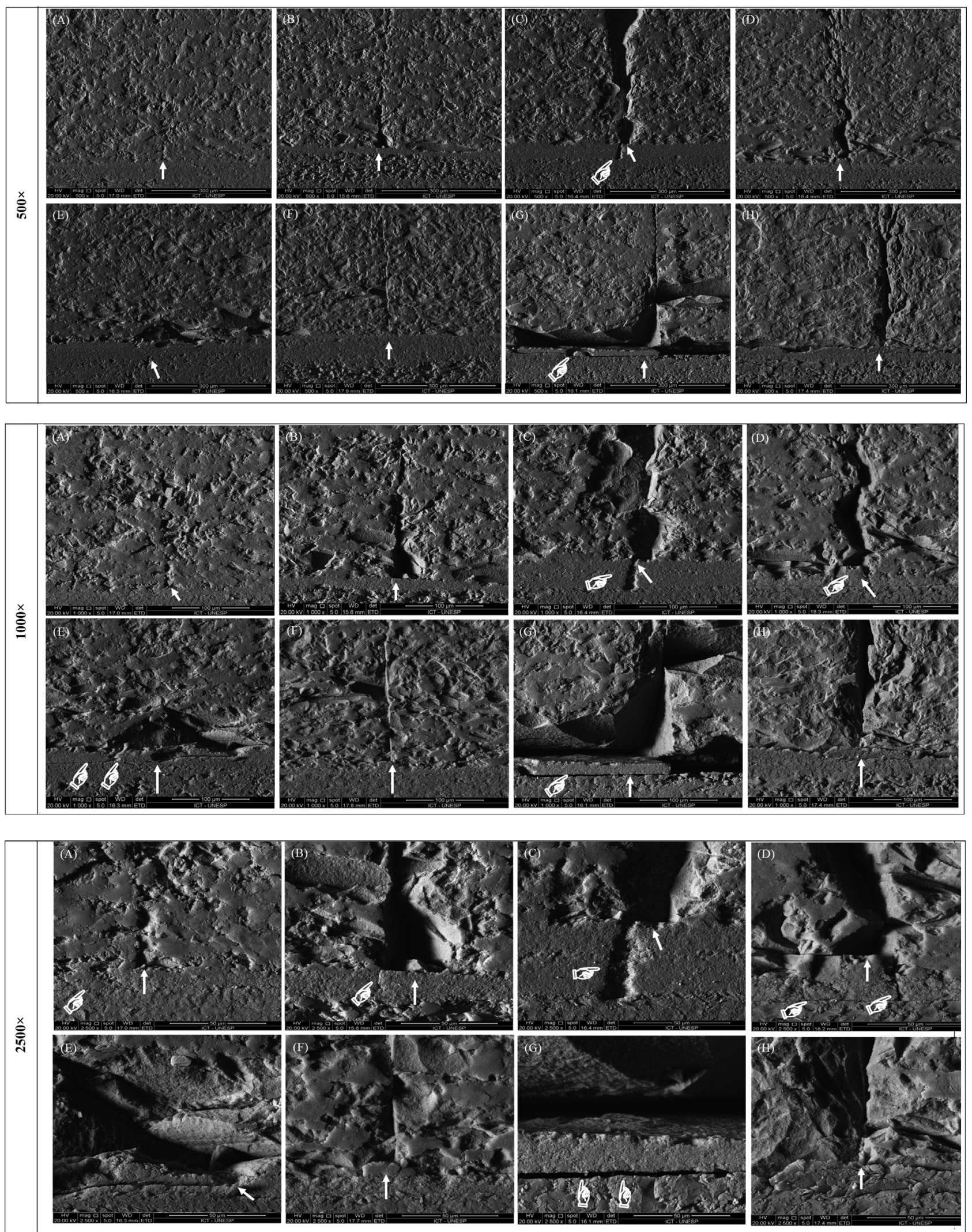

Fig. 2 - Representative micrographs of failed assemblies after fatigue tests (original magnification of 500x, 1000x, 2500x). Suprinity (A-D) and Celtra Duo (E-H) on thicknesses of 1.0, 1.5, 2.0 and $2.5 \mathrm{~mm}$, respectively. The arrows and pointers indicate the failure origin. 


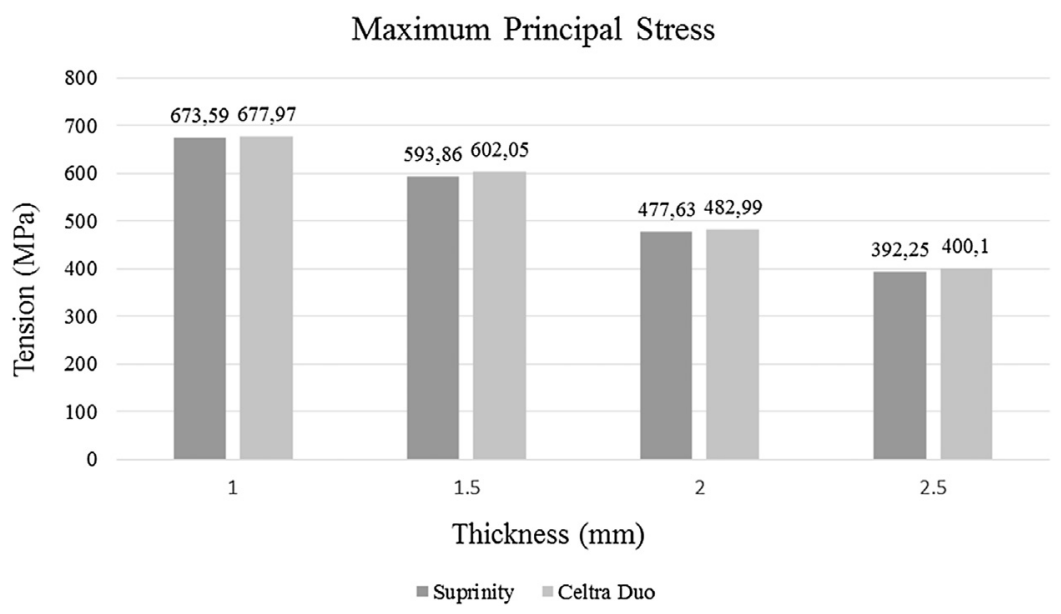

Fig. 3 - Maximum principal stress observed in FEA models of Suprinity and Celtra Duo at different thicknesses, on which the load was applied by a stainless-steel spherical piston $(40 \mathrm{~mm}$ of diameter).
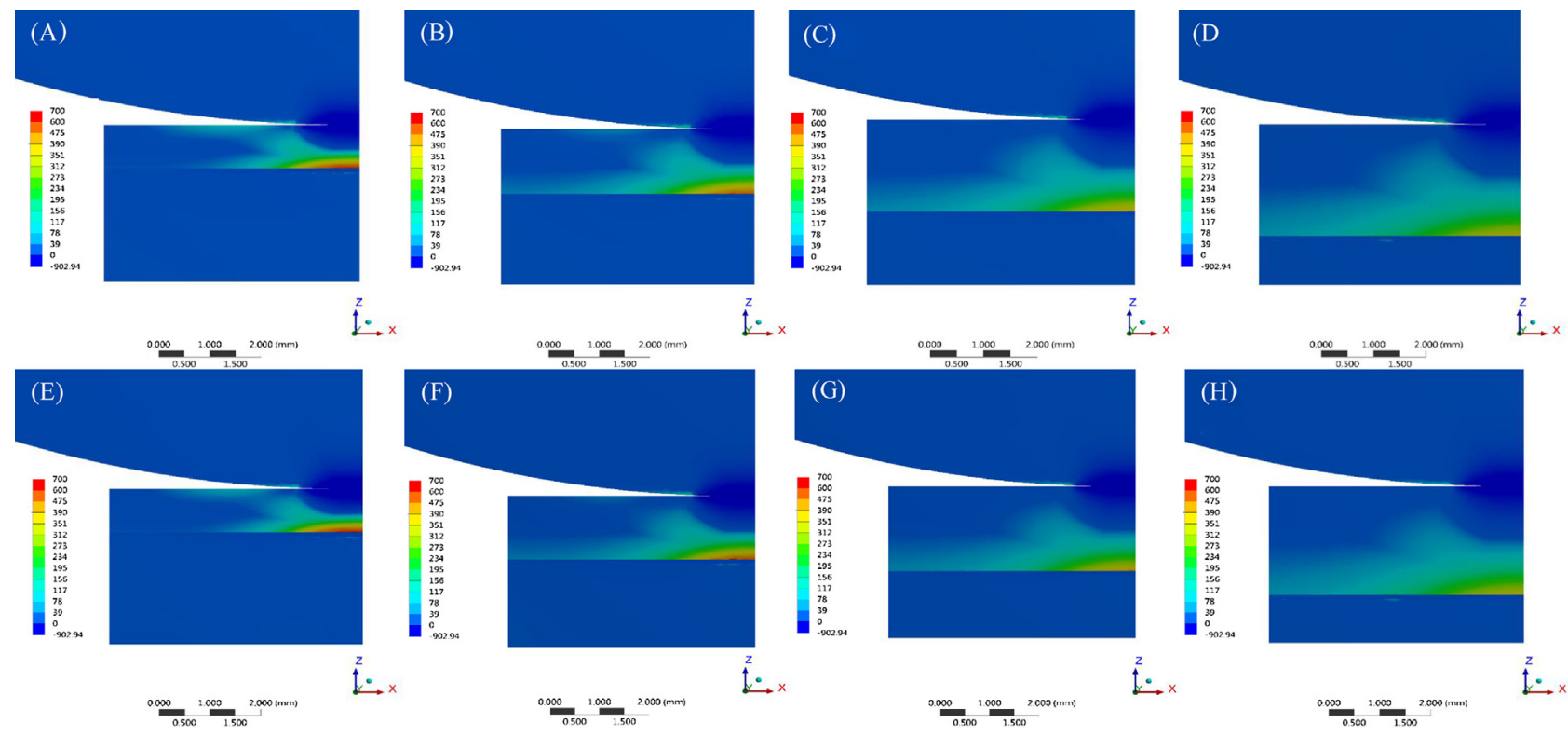

Fig. 4 - Distribution of the maximum principal stress on the specimens: Suprinity (A-D) and Celtra Duo (E-H) on thicknesses of 1.0, 1.5, 2.0 and $2.5 \mathrm{~mm}$, respectively, loaded with a stainless-steel spherical piston $(\phi=40 \mathrm{~mm})$.

\subsection{Fractographic analysis}

Fractographic analysis under a light microscope showed that all failures started from the cementation surface as radial cracks. Fig. 2 shows representative SEM micrographs of radial cracks. It is possible to observe fractures starting from defects located on the tensile surface of the ceramic (i.e., on the cementation surface).

\subsection{Finite Element Analysis}

The results of the Maximum Principal Stress (MPa) analyses are presented in Figs. 3 and 4. It shows that the Maximum Principal Stress for the same thicknesses was similar for both ZLS ceramics. Higher stresses were generated at the cementing interface of thinner specimens.

\section{Discussion}

Since our findings depicted that thicker ZLS glass-ceramic restorations presents higher fatigue failure loads, the first tested hypothesis was accepted. Also, the current findings highlight a potential influence of the materials' microstructure on the crack propagation and fatigue behavior of the ZLS glass-ceramics, partially denying the second null hypothesis. Thus, the fatigue failure load of the evaluated assembly was affected by both factors: "ZLS ceramic type" and "ceramic thickness".

Literature shows a lack of consensus regarding the influence of thickness on the strength of a restorative assembly (ceramic restoration cemented to tooth substrates). Some state that reduced occlusal ceramic thickness may have a 
negative effect on the mechanical properties of the material, since the ceramic strength is inversely related to the square of the ceramic thickness [10]. Our data corroborate this issue, as when the assembly was submitted to fatigue loads in a wet environment, the thickness affected the final fatigue failure load of the ZLS glass-ceramic restorations. On the other hand, it has been reported that the use of adhesive cementation techniques (resin cement) could improve the survival probability of ceramic restorations, because enhanced adhesion can promote structural reinforcement, independent of the material thickness [33-35].

When an adequate adhesion is achieved among ceramic restoration, resin cement and tooth structure, the stress distribution of the applied load is enhanced through the system. In this scenario, existing literature supports that a restoration's thickness will not be important for defining the fracture resistance of the system $[34,36]$. According to Bakeman et al. [34], changes in ceramic thickness have minimal influence on the overall flexural strength of the material, thus suggesting the possibility of decreasing to $1 \mathrm{~mm}$ thickness for lithium disilicate ceramic restorations when effectively bonded to the underlying tooth structure. However, these premises were not corroborated by the current study for ZLS glass-ceramics, since, even adhesively cemented in extremely standardized, reproducible and controlled procedures, thinner ceramic restorations presented lower fatigue failure loads.

Additionally, it is important to highlight that FEA analyses clearly indicate that a variation in ceramic thickness influences the stress distribution: thinner thickness leads to higher stress concentration in the samples on the cementing interface. Theoretically, in an ideal situation, both materials had the same mechanical behavior, because the tensile stresses were similar for the same thicknesses. Higher stresses will lead to early failure, which is in line with our findings in the fatigue tests, and is in accordance with Ma et al. [37]. Interpreting these findings, it can be concluded that, as the higher stress concentration is located at the cementing interface, the probable origin of fracture will be in this zone, which is in accordance with the clinical origin of fractures [20,38,39], and with the fracture pattern observed in our study.

As previously described, both evaluated ceramic materials are consisted of ZLS glass-ceramics with similar composition [1], however our data supports distinct behaviors in terms of fatigue failure load. The explanation could be focused on the different microstructural arrangement of the ceramics [submicrometric (up to $\sim 1 \mu \mathrm{m}$ in length) lithium metasilicate crystallites - Celtra Duo $\times$ nanometric $(\sim 0.5 \mu \mathrm{m})-$ Vita Suprinity], since higher values of fatigue failure load were find when the ZLS ceramic presented nanometric lithium metasilicate crystallites compared to submicrometric ones.

Denry and Holloway [40] stated that the microstructure achieved by interlocking crystals in addition to their alignment might play an important role in hindering crack propagation; in this sense, the nano-structured material appears to present a more interlocked microstructure, supporting the high values of fatigue failure load found for this ZLS glass-ceramic. Also, reviews on this topic $[5,6]$ conclude that the stress yield and microhardness of nanocrystalline materials can be 2 up to 10 times higher than the corresponding coarse-grained material, with the same chemical composition. In summary, the proved mechanism is based on the fact that smaller grains limit the size of dislocations on the crystal grain boundaries, affecting the transposition of the stimuli from grain to grain. Therefore, a higher applied stress is required to induce permanent material deformation, or fracture in the case of ceramics (brittle nature) $[5,6]$.

It is clear that the long-term success of ceramic restorations is not only influenced by ceramic material characteristics (composition, processing, and thickness, among other factors), but also by the inherent characteristics of the remaining tooth structure and the bonding protocol implemented (quality of adhesion obtained) [34]. Thus, more studies should be incentivized in attempt to enhance those factors and improve the long-term success of such restorations.

It is important to highlight that the lack of literature consensus regarding this thematic may also be explained by the high heterogeneity and variability among the employed methodologies and additional biasing factors, especially considering an in vitro study design. In this sense, in order to simulate a clinical setup (as close as possible), we used a resin epoxy supporting material that mimics human hydrated dentin in terms of resin cement bond strength and blunt contact elastic behavior as it presents an elastic modulus (18 MPa) similar to that of human dentin $[20,41]$. Besides, the observed fracture pattern was similar to that one observed on clinically failed restorations [20].

Even though some studies have reported failures starting from the cervical margin, bulk fractures arising from the cementation surface of ceramic restorations remain as the primary clinically-observed failure modes [20,38,39]. The methodology for specimen preparation preconized by Kelly et al. [20] and used in the current study assures that pattern of failure. On the other hand, an important limitation is that dental crowns typically present complex geometry, and flatted specimens (as used in the present study) are not able to completely reproduce this complexity. In addition, occlusion not only implicates axial loads, but also different contact places and sliding. This is different from the present study where a stainless-steel piston applied an axial load only in the center of the specimens. However, they support some investigations of isolated factors (e.g., influence of material thickness, different ceramic compositions, etc.), enabling an evaluation about mechanical behavior and material properties. Another aspect is the frequency used during fatigue testing. Low frequencies make data collection very time-consuming; in this sense, Fraga et al. [16] noticed that accelerated fatigue methods (up to $20 \mathrm{~Hz}$ ) do not influence the collected data for yttria partially stabilized tetragonal zirconia.

\section{Conclusion}

- Different ZLS glass-ceramics thicknesses influenced the fatigue failure load of the bonded system (i.e. the thicker the ZLS glass-ceramic is, the higher the fatigue failure load will be).

- The different microstructures of the ZLS glass-ceramics might affect fatigue behavior of restorations. 
- As verified from FEA findings, the thicker the glass ceramic is, the lower the stress concentration at the tension surface will be.

\section{REFERENCES}

[1] Belli R, Wendler M, de Ligny D, Cicconi MR, Petschelt A, Peterlik H, et al. Chairside CAD/CAM materials. Part 1: measurement of elastic constants and microstructural characterization. Dent Mater 2017;33(1):84-98.

[2] Mante FK, Ozer F, Walter R, Atlas AM, Saleh N, Dietschi D, et al. The current state of adhesive dentistry: a guide for clinical practice. Compend Contin Educ Dent 2013;34:2-8.

[3] Awad D, Stawarczyk B, Liebermann A, Ilie N. Translucency of esthetic dental restorative CAD/CAM materials and composite resins with respect to thickness and surface roughness. J Prosthet Dent 2015;113(6):534-40.

[4] Schwindling FS, Rues S, Schmitter M. Fracture resistance of glazed, full-contour ZLS incisor crowns. J Prosthodont Res 2017;61(3):344-9.

[5] Palmero P. Structural ceramic nanocomposites: a review of properties and powders synthesis methods. Nanomaterials (Basel) 2015;5(2):656-96.

[6] Pande CS, Cooper KP. Nanomechanics of hall-petch relationship in nanocrystalline materials. Progr Mater Sci 2009;54:689-706

[7] Aboushelib MN, Sleem D. Microtensile bond strength of lithium disilicate ceramics to resin adhesives. J Adhes Dent 2014; 16:547-52.

[8] Elsaka SE, Elnaghy AM. Mechanical properties of zirconia reinforced lithium silicate glass-ceramic. Dent Mater 2016;32(7):908-14.

[9] Peumans M, Valjakova EB, De Munck J, Mishevska CB, Van Meerbeek B. Bonding effectiveness of luting composites to different CAD/CAM materials. J Adhes Dent 2016;18(4):289-302.

[10] Seghi RR, Daher T, Caputo A. Relative flexural strength of dental restorative ceramics. Dent Mater 1990;6(3):181-4.

[11] Chen C, Trindade FZ, de Jager N, Kleverlaan CJ, Feilzer AJ. The fracture resistance of a CAD/CAM Resin Nano Ceramic (RNC) and a CAD ceramic at different thicknesses. Dent Mater 2014;30(9):954-62.

[12] Al-Makramani BMA, Razak AAA, Abu-Hassan MI. Evaluation of load at fracture of Procera AllCeram copings using different luting cements. J Prosthodont 2008;17(2):120-4.

[13] Zhang Y, Lawn BR. Fatigue sensitivity of Y-TZP to microscale sharp-contact flaws. J Biomed Mater Res B Appl Biomater 2005;72(2):388-92.

[14] Bhowmick S, Meléndez-Martínez JJ, Zhang Y, Lawn BR. Design maps for failure of all-ceramic layer structures in concentrated cyclic loading. Acta Mater 2007;55(7):2479-88.

[15] Gressler May L, Kelly JR, Bottino MA, Hill T. Influence of the resin cement thickness on the fatigue failure loads of CAD/CAM feldspathic crowns. Dent Mater 2015;31(8):895-900.

[16] Fraga S, Pereira GK, Freitas M, Kleverlaan CJ, Valandro LF, May LG. Loading frequencies up to $20 \mathrm{~Hz}$ as an alternative to accelerate fatigue strength tests in a Y-TZP ceramic. J Mech Behav Biomed Mater 2016;61:79-86.

[17] Venturini AB, Prochnow C, May LG, Kleverlaan CJ, Valandro LF. Fatigue failure load of feldspathic ceramic crowns after hydrofluoric acid etching at different concentrations. J Prosthet Dent 2017:30237-8, piiS0022-3913(17).

[18] Villefort RF, Amaral M, Pereira GKR, Campos TM, Zhang Y Bottino MA, et al. Effects of two grading techniques of zirconia material on the fatigue limit of full-contour 3-unit fixed dental prostheses. Dent Mater 2017;33(4):e155-64

[19] Zucuni CP, Guilardi LF, Fraga S, May LG, Pereira GKR, Valandro LF. CAD/CAM machining vs pre-sintering in-lab fabrication techniques of Y-TZP ceramic specimens: Effects on their mechanical fatigue behavior. J Mech Behav Biomed Mater 2017;71:201-8.

[20] Kelly JR, Rungruanganunt P, Hunter B, Vailati F. Development of a clinically validated bulk failure test for ceramic crowns. J Prosthet Dent 2010;104(4):228-38.

[21] Kelly JR, Cesar PF, Scherrer SS, Della Bona A, van Noort R, Tholey M, et al. ADM guidance-ceramics: fatigue principles and testing. Dent Mater 2017;33(11):1192-204.

[22] Monteiro JB, Oliani MG, Guilardi LF, Prochnow C, Pereira GKR Bottino MA, et al. Fatigue failure load of zirconia-reinforced lithium silicate glass ceramic cemented to a dentin analogue: effect of etching time and hydrofluoric acid concentration. J Mech Behav Biomed Mater 2018;23(77):375-82.

[23] Ferrario VF, Sforza C, Tartaglia GM, Colombo A, Serrao G. Size and shape of the human first permanent molar: a Fourier analysis of the occlusal and equatorial outlines. Am J Phys Anthropol 1999;108(3):281-94.

[24] Sulieman M, Addy M, Rees JS. Surface and intra-pulpal temperature rises during tooth bleaching: an in vitro study. Braz Dent J 2005;199:37-40.

[25] Anami LC, Lima JM, Valandro LF, Kleverlaan CJ, Feilzer AJ, Bottino MA. Fatigue resistance of Y-TZP/porcelain crowns is not influenced by the conditioning of the intaglio surface. Oper Dent 2016;41(1):E1-12.

[26] Campos F, Valandro LF, Feitosa SA, Kleverlaan CJ, Feilzer AJ, de Jager $\mathrm{N}$, et al. Adhesive cementation promotes higher fatigue resistance to zirconia crowns. Oper Dent 2017;42(2):215-24.

[27] Wachtman Jr JB, Capps W, Mandel J. Biaxial flexure tests of ceramic substrates. J Mater 1972;7:188-94.

[28] Venturini AB, Prochnow C, Pereira GKR, Werner A, Kleverlaan CJ, Valandro LF. The effect of hydrofluoric acid concentration on the fatigue failure load of adhesively cemented feldspathic ceramic discs. Dent Mater 2018;S0109-5641(17), 31065-5.

[29] Collins JA. Failure of materials in mechanical design: analysis, prediction, prevention. second edition A Willey Interscience Publication, John Willey \& Sons; 1993. p. 383-8.

[30] Dixon WJ, Mood AM. A method for obtaining and analyzing sensitivity data. J Am Stat Assoc 1948;43:109-26.

[31] Pereira GKR, Silvestri T, Amaral M, Rippe MP, Kleverlaan CJ, Valandro LF. Fatigue limit of polycrystalline zirconium oxide ceramics: effect of grinding and low-temperature aging. J Mech Behav Biomed Mater 2016;61:45-54.

[32] Wakabayashi N, Ona M, Suzuki T, Igarashi Y. Nonlinear finite element analyses: advances and challenges in dental applications. J Dent 2008;36(7):463-71.

[33] Hamburger JT, Opdam NJ, Bronkhorst EM, Huysmans MC. Indirect restorations for severe tooth wear: fracture risk and layer thickness. J Dent 2014;42(4):413-8, http://dx.doi.org/10.1016/j.jdent.2013.10.003.

[34] Bakeman EM, Rego N, Chaiyabutr Y, Kois JC. Influence of ceramic thickness and ceramic materials on fracture resistance of posterior partial coverage restorations. Oper Dent 2015;40(2):211-7.

[35] Sasse M, Krummel A, Klosa K, Kern M. Influence of restoration thickness and dental bonding surface on the fracture resistance of full-coverage occlusal veneers made from lithium disilicate ceramic. Dent Mater 2015;31(8):907-15. 
[36] Proos KA, Swain MV, Ironside J, Steven GP. Influence of cement on a restored crown of a first premolar using finite element analysis. Int J Prosthodont 2003;16(1):82-90.

[37] Ma L, Guess PC, Zhang Y. Load-bearing properties of minimal-invasive monolithic lithium disilicate and zirconia occlusal onlays: finite element and theoretical analyses. Dent Mater 2013;29:742-51.

[38] Qasim T, Ford C, Bush MB, Hu X, Lawn BR. Effect of off-axis concentrated loading on failure of curved brittle layer structures. J Biomed Mater Res B Appl Biomater 2006;76(2):334-9.

[39] Anusavice KJ. Standardizing failure, success, and surviva] decisions in clinical studies of ceramic and metal-ceramic fixed dental prostheses. Dent Mater 2012;28(1):102-11.

[40] Denry IL, Holloway JA. Effect of post-processing heat treatment on the fracture strength of a heat-pressed dental ceramic. J Biomed Mater Res B Appl Biomater 2004;68: 174-9.
[41] Wang Y, Katsube N, Seghi RR, Rokhlin SI. Statistical failure analysis of adhesive resin cement bonded dental ceramics. Eng Fract Mech 2007;74:1838-56.

[42] Ramos NC, Campos TM, Paz IS, Machado JP, Bottino MA, Cesar PF, et al. Microstructure characterization and SCG of newly engineered dental ceramics. Dent Mater 2016;32(7):870-8.

[43] Lawson NC, Bansal R, Burgess JO. Wear, strength, modulus and hardness of CAD/CAM restorative materials. Dent Mater 2016;32(11):e275-83.

[44] Liu B, Lu C, Wu Y, Zhang X, Arola D, Zhang D. The effects of adhesive type and thickness on stress distribution in molars restored with all-ceramic crowns. J Prosthodont 2011;20(1):35-44. 